\title{
Video Article \\ Ultrasensitive Detection of Biomarkers by Using a Molecular Imprinting Based Capacitive Biosensor
}

\author{
Gizem Ertürk ${ }^{1}$, Rolf Lood ${ }^{1}$ \\ ${ }^{1}$ Department of Clinical Sciences Lund, Division of Infection Medicine, Lund University
}

Correspondence to: Rolf Lood at rolf.lood@med.lu.se

URL: https://www.jove.com/video/57208

DOI: doi:10.3791/57208

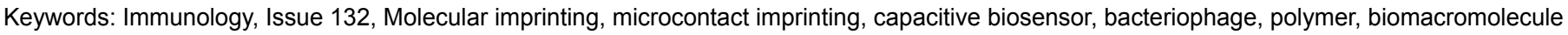

Date Published: 2/16/2018

Citation: Ertürk, G., Lood, R. Ultrasensitive Detection of Biomarkers by Using a Molecular Imprinting Based Capacitive Biosensor. J. Vis. Exp. (132), e57208, doi:10.3791/57208 (2018).

\section{Abstract}

The ability to detect and quantitate biomolecules in complex solutions has always been highly sought-after within natural science; being used for the detection of biomarkers, contaminants, and other molecules of interest. A commonly used technique for this purpose is the Enzymelinked Immunosorbent Assay (ELISA), where often one antibody is directed towards a specific target molecule, and a second labeled antibody is used for the detection of the primary antibody, allowing for the absolute quantification of the biomolecule under study. However, the usage of antibodies as recognition elements limits the robustness of the method; as does the need of using labeled molecules. To overcome these limitations, molecular imprinting has been implemented, creating artificial recognition sites complementary to the template molecule, and obsoleting the necessity of using antibodies for initial binding. Further, for even higher sensitivity, the secondary labeled antibody can be replaced by biosensors relying on the capacitance for the quantification of the target molecule. In this protocol, we describe a method to rapidly and labelfree detect and quantitate low-abundant biomolecules (proteins and viruses) in complex samples, with a sensitivity that is significantly better than commonly used detection systems such as the ELISA. This is all mediated by molecular imprinting in combination with a capacitance biosensor.

\section{Video Link}

The video component of this article can be found at https://www.jove.com/video/57208/

\section{Introduction}

The quantification of biomolecules is used in many different research fields within science, employing methods like the radioimmunoassay (RIA) or ELISA ${ }^{1}$. Some of these methods require a labeled reagent like a radioisotope or enzyme labeled antibody/antigen, which makes them laborintensive and time-consuming with complex procedures ${ }^{2}$. Further, the robustness, selectivity, and sensitivity of these methods are not sufficient for all analyses; in particular they are not sufficient when attogram quantities need to be analyzed, rather than pictogram quantities ${ }^{3}$. For this purpose, biosensors have gained considerable interest ${ }^{4,5}$, in particular in combination with molecular imprinting for an increased robustness.

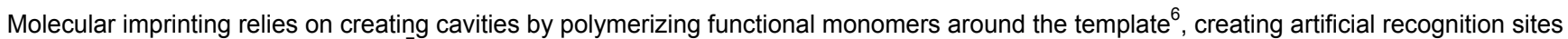
that perfectly resemble the template ${ }^{7}$. This technique has been used for several applications, including drug delivery systems and analytical separation, but also as biorecognition elements in biosensors ${ }^{8,9,10}$. However, there are still some difficulties in the design of molecularly imprinted polymers (MIPs) for macromolecular templates like proteins and cells ${ }^{11,12}$. Due to this, many researchers have focused on imprinting the template protein directly onto a substrate, thus creating a surface that will be recognized by the target protein ${ }^{12}$. This surface coating technique used for employing recognition cavities for large molecules and assemblies including proteins is called microcontact imprinting ${ }^{13,14}$. The general procedure of the method depends on the polymerization between two surfaces - a template stamp and a polymer support - upon which the template is adsorbed on one surface ${ }^{15,16}$, and brought into contact with the monomer-treated surface. By this way, a thin polymer film is formed on the support via UV-polymerization. Finally, the template is removed, leaving behind template specific cavities at the surface of the imprinted electrode. This method has some advantages including a reduced activity loss of the imprinted molecule, as well as requiring very small amounts of template molecules for the imprinting process ${ }^{16,17}$. Thus, these cost-effective, stable, sensitive, and selective surfaces can be created on the sensor surfaces, targeting any template of the user's choice.

The biosensor can be used for the detection of single proteins and much larger biomacromolecules, including viruses. A specific group of viruses gaining recent interest is the bacteriophage, which is a virus that infects bacteria. Quick and sensitive detection of bacteriophages is important during biotechnological and biopharmaceutical processes in order to determine the infections of bacterial cultures with bacteriophages ${ }^{18}$. The most commonly used biological assay for bacteriophage detection is the double layer agar method ${ }^{19}$, which is laborious and time consuming. Several attempts have been made to develop novel diagnostic tools for viruses (including bacteriophages) such as atomic force microscopy $(\mathrm{AFM})^{20}$, interferometry ${ }^{21}$, electrochemistry ${ }^{22}$, and sensor system ${ }^{23,24}$. A lot of work has been focused on biosensors owing to their advantages as being easy to operate, highly sensitive, and capable of real-time measurement ${ }^{15,25}$. A specific type of biosensor is based on changes in capacitance. These capacitive biosensors are the electrochemical sensors that measure changes in the dielectric properties when an analyte interacts with a biorecognition element on the sensor surface, causing a decrease in the capacitance ${ }^{2,4}$. Capacitive biosensors have been used 
for the detection of various analytes like antigens, antibodies, proteins, and heavy metal ions ${ }^{6,26,27,28}$. These types of biosensors have many advantages like inherent rapidity, high sensitivity, simplicity, low cost, easy manipulation, and real-time measurement without labeling ${ }^{29}$.

The method described herein is aimed at enabling the detection and quantification of low-abundant biomolecules in highly complex samples, without the need of using any labeling. In particular, the technique is most useful in the atto-picogram range of biomolecules, where other commercially existing instruments fail to accurately quantitate their target.

\section{Protocol}

\section{Modification of Glass Cover Slips (Template Stamps)}

1. To clean the glass cover slips, immerse them sequentially in $10 \mathrm{~mL}$ of $1.0 \mathrm{M} \mathrm{HCl}$, deionized water, and $1.0 \mathrm{M}$ of $\mathrm{NaOH}$, respectively, for 10 min in each step in an ultrasonic cleaner at room temperature.

1. Dry the glass cover slips with nitrogen gas.

NOTE: The cover slips are dried by evaporation under a stream of gaseous nitrogen.

2. Immerse the cleaned and dried cover slips in $10 \%(\mathrm{v} / \mathrm{v}), 10 \mathrm{~mL}$ solution of 3-amino-propyl-triethoxysilane (APTES) in ethanol for $1 \mathrm{~h}$ to introduce amino groups on the cover glass surface, at room temperature.

1. Rinse the cover slips with deionized water.

2. Dry the cover slips with nitrogen gas.

3. Immerse the APTES-modified cover slips in $5 \%(\mathrm{v} / \mathrm{v}), 10 \mathrm{~mL}$ solution of glutaraldehyde in $10 \mathrm{mM}$ phosphate buffer $(\mathrm{pH} 7.4)$ for $2 \mathrm{~h}$ in order to activate the amino groups on the surface, at room temperature ${ }^{6,15}$

1. Rinse the cover slips with $10 \mathrm{mM}$ phosphate buffer $(\mathrm{pH} 7.4)$ in order to remove excess glutaraldehyde from the surface.

2. Dry the cover slips with nitrogen gas.

4. Prepare $1.0 \mathrm{~mL}$ of template (protein/bacteriophage) solution in $10 \mathrm{mM}$ phosphate buffer $(\mathrm{pH} 7.4)$ in $0.1 \mathrm{mg} / \mathrm{mL}$ concentration. NOTE: Dissolve $0.1 \mathrm{mg}$ of protein in $1.0 \mathrm{~mL}$ of phosphate buffer $(10 \mathrm{mM}, \mathrm{pH} 7.4)$. If needed, a spectrophotometer (280 nm) may be used to determine the protein concentration.

1. Drop $200 \mu \mathrm{L}$ of this template solution onto the modified cover slips and incubate at $4{ }^{\circ} \mathrm{C}$ overnight. NOTE: The excess template solution can be used to prepare $1-2$ more template stamps to be used in the characterization studies.

2. Rinse the cover slips with $10 \mathrm{mM}$ phosphate buffer $(\mathrm{pH} 7.4)$ in order to remove the unbound template from the surface. NOTE: To rinse the electrodes, wash them with phosphate buffer $(10 \mathrm{mM}, \mathrm{pH} 7.4)$ for $30 \mathrm{~s}$.

3. Dry the cover slips with nitrogen gas. NOTE: The cover slips should be stored at $4{ }^{\circ} \mathrm{C}$ until they are used in the polymerization step.

\section{Modification of Capacitive Gold Electrodes}

1. To clean the electrodes, immerse the electrodes in a small beaker, sequentially, containing $5 \mathrm{~mL}$ of ethanol (70\%), deionized water, acetone, deionized water, acidic piranha solution $\left(3: 1, \mathrm{H}_{2} \mathrm{SO}_{4}: \mathrm{H}_{2} \mathrm{O}_{2}, \mathrm{v} / \mathrm{v}\right)$, and deionized water, respectively for 10 min in each step, in an ultrasonic cleaner at room temperature.

1. Dry the electrodes with nitrogen gas.

2. In order to perform the electropolymerization of tyramine, prepare $8 \mathrm{~mL}$ of $10 \mathrm{mM}$ tyramine solution in $10 \mathrm{mM}$ phosphate buffer (pH 7.4 ) containing ethanol $(2 \mathrm{~mL})^{15}$.

NOTE: The total volume of the tyramine solution must be $8 \mathrm{~mL}$ in total including $2 \mathrm{~mL}$ of ethanol.

1. Perform cyclic voltammetric scans ( 15 cycles) in this solution using a potentiostat covering a potential range of $0-1.5 \mathrm{~V}(\mathrm{Ag} / \mathrm{AgCl})$ and a scan rate of $50 \mathrm{mV} / \mathrm{s}^{30}$.

2. Rinse the electrodes with deionized water.

3. Dry the electrodes with nitrogen gas.

3. Immerse the electrodes in a solution containing $30 \mathrm{mM}$ acryloyl chloride and $30 \mathrm{mM}$ trimethylamine in toluene $\left(\mathrm{V}_{\text {total }}=5 \mathrm{~mL}\right)$ at room temperature overnight ${ }^{6,15,30}$.

1. Rinse the electrodes with deionized water. NOTE: To ensure a better removal of unreacted acryloyl chloride and trimethylamine residues, it is also possible to wash the surface with $\mathrm{NaOH}$ after deionized water.

2. Dry the electrodes with nitrogen gas.

\section{Preparation of Template Imprinted Capacitive Gold Electrodes}

1. Preparation of bacteriophage imprinted capacitive gold electrodes

1. Prior to polymerization, prepare a monomer solution containing monomer ( $\mathrm{N}$-hydroxymethyl acrylamide) and cross-linker (polyethylene glycol-400-dimethacrylate) in a ratio of $1: 5(\mathrm{~mol} / \mathrm{mol})$ in $1 \mathrm{~mL}$ of $10 \mathrm{mM}$ phosphate buffer $(\mathrm{pH} 7.4)$. NOTE: The monomer solution containing monomer and cross-linker can be used in different ratios, or the types of the monomer and cross-linker can be changed according to the template for optimization of the specific interaction.

2. Add $1 \mathrm{mg}$ of photo-initiator into this solution. 
NOTE: If the polymerization is performed under UV light, then the photo-initiator must be used to initiate the polymerization. If the polymerization is performed by free radical polymerization, the type of the initiator must be changed.

3. Pipette $1.5 \mu \mathrm{L}$ of this solution onto the gold surface of the modified gold electrode.

NOTE: The gold surface of the electrode is shown schematically in Figure 1.

4. Bring the template stamp in contact with the monomer solution on the top of the gold electrode surface.

5. Initiate the UV polymerization ( $365 \mathrm{~nm}, 400 \mathrm{~W}$ ) and continue for $15 \mathrm{~min}^{31}$.

NOTE: UV polymerization is performed inside a cooling cabinet which is set to $-25^{\circ} \mathrm{C}$ before initiating polymerization. Then, the UV light curing system is turned on and the polymerization is continued for 15 min before turning off the UV light curing system.

6. Remove the template stamp from the surface by using forceps.

NOTE: While removing the template stamp from the surface, the polymeric film on the surface may be damaged. Therefore, the stamp should be removed from the surface very carefully and slowly without using force.

7. Rinse the electrode surface with deionized water and dry it with nitrogen gas.

8. Immerse the electrodes in $1 \mathrm{~mL}$ of $10 \mathrm{mM}$ 1-dodecanethiol prepared in ethanol for $20 \mathrm{~min}$ in order to cover pinholes on the electrode surface.

9. Rinse the electrodes with deionized water and dry the electrodes with nitrogen gas.

\section{Preparation of Protein Imprinted Capacitive Gold Electrodes}

1. Prior to polymerization, prepare a monomer solution containing monomers (acrylamide: $54 \mathrm{mg} ; \mathrm{N}$-hydroxymethylacrylamide: $140 \mu \mathrm{L} ; \mathrm{N}$ isopropylacrylamide: $85.6 \mathrm{mg}$ ) and cross-linker (methylenebisacrylamide: $9.5 \mathrm{mg}$ ) in $820 \mu \mathrm{L}$ of ultra-pure water ${ }^{30,32}$.

2. Prepare $5 \%(\mathrm{v} / \mathrm{v}) \mathrm{N}, \mathrm{N}, \mathrm{N}^{\prime}, \mathrm{N}^{\prime}$-tetramethylethyldiamine (TEMED) in ultra-pure water

3. Add $20 \mu \mathrm{L}$ of the TEMED solution into the monomer solution and purge with nitrogen gas for $5 \mathrm{~min}$.

4. Prepare $10 \%(\mathrm{w} / \mathrm{v})$ ammonium persulphate (APS) in ultra-pure water.

5. Add $20 \mu \mathrm{L}$ of the APS solution into the monomer solution.

6. Pipette $1.5 \mu \mathrm{L}$ of the monomer solution onto the modified gold electrode surface.

7. Bring the template stamp into contact with the monomer-treated surface.

8. Start polymerization at room temperature and continue for $5 \mathrm{~h}$. NOTE: For the preparation of protein-imprinted gold electrodes, instead of UV-polymerization, free-radical polymerization at room temperature $\left(25^{\circ} \mathrm{C}\right)$ is performed by using APS-TEMED as the initiator-catalyst.

9. Remove the template stamp from the surface carefully by using forceps.

10. Rinse the electrode with deionized water and dry with nitrogen gas.

11. Immerse the electrodes in $1 \mathrm{~mL}$ of $10 \mathrm{mM}$ 1-dodecanethiol prepared in ethanol for $20 \mathrm{~min}$ in order to cover pinholes on the electrode surface.

12. Rinse the electrodes with deionized water and dry the electrodes with nitrogen gas.

\section{Characterization of the Electrode Surface with Scanning Electron Microscopy (SEM)}

1. Mount the specimens on aluminum holders with adhesive carbon tape.

2. Coat the electrodes with $10 \mathrm{~nm}$ palladium/gold.

3. Examine the electrodes with SEM.

\section{Real-time Capacitive Measurements with Template Imprinted Capacitive Gold Electrodes}

1. Insert the imprinted capacitive gold electrodes into the electrochemical flow cell integrated to a capacitive biosensor.

2. Prepare $100 \mathrm{~mL}$ of regeneration buffer $(25 \mathrm{mM}$ glycine- $\mathrm{HCl}, \mathrm{pH} 2.5$, including $50 \mathrm{mM}$ Tween-20) and $1 \mathrm{~L}$ running buffer (for bacteriophage imprinted system: $10 \mathrm{mM}$ phosphate, $\mathrm{pH}$ 7.4; for protein-imprinted system: $50 \mathrm{mM}$ Tris- $\mathrm{HCl}, \mathrm{pH} 7.4$ ).

3. Start the analysis with the injection of regeneration buffer to regenerate the system and running buffer to re-equilibrate the system for 25 min.

4. Prepare standard template solutions in the desired concentration range in running buffer. NOTE: First prepare a stock of the template solution by dissolving $0.1 \mathrm{mg}$ protein, or approximately $10^{8}$ pfu bacteriophages, in $1.0 \mathrm{~mL}$ phosphate buffer (10 mM phosphate, $\mathrm{pH}$ 7.4). Then, prepare the standard solutions for the calibration curve by making ten sequential 10fold dilutions from the stock solution. These solutions will be analyzed with the capacitive biosensor in step 5.5. Protein concentration can be measured by using a spectrophotometer $(280 \mathrm{~nm})$. In order to measure the bacteriophage concentration, a double layer agar method can be used, which is described in details previously ${ }^{19}$.

5. Inject $250 \mu \mathrm{L}$ of these standard solutions sequentially to the system in optimum conditions (flow rate: $100 \mu \mathrm{L} / \mathrm{min}$, temperature: $25^{\circ} \mathrm{C}$ ). NOTE: In this application, the standard protein solutions were prepared in the concentration range of $1.0 \times 10^{-4}-1.0 \times 10^{-14}$, while the bacteriophage concentrations were in the range $1.0 \times 10^{1}-1.0 \times 10^{5} \mathrm{pfu} / \mathrm{mL}$. The solutions were placed in the injection valve, and sequentially injected into the system, injecting the samples in triplicates through the single syringe pump and the multiport valve. The decrease in capacitance after injecting the standard solutions arising from the binding of template to the imprinted cavities is monitored automatically by the instrument's software.

\section{Representative Results}

By following the protocol, according to the schematic in Figure 1, a bare gold electrode will be imprinted with a template, representing the structure of a biomacromolecule. This electrode can be applied in a capacitive biosensor (Figure 2), allowing the stable application of a template onto the electrode, and the measurement of changes in capacitance upon binding of the template. 
A schematic representation of the capacitive biosensor is shown in Figure 2. The centris pump, which is responsible for continuous injection of the running buffer $(10 \mathrm{mM}$ phosphate, $\mathrm{pH} 7.4)$, and the regeneration buffer $(25 \mathrm{mM}$ glycine- $\mathrm{HCl}, \mathrm{pH} 2.5)$ during regeneration into the flow cell, can be seen clearly in the figure. The flow cell consists of working, reference, and counter electrodes. The injection valve is composed of standard protein/bacteriophage solutions, which are passing through the degasser first and then injected sequentially into the system. As soon as the solutions reach the working electrode inserted in the flow cell, the result is monitored in real-time. The capacitance values can be registered by following the sensorgrams on the computer screen.

Figure 3 and Figure 4 depict the differences between the surface of bare and imprinted gold electrodes. This characterization step is important to ensure that there are polymeric cavities, seen as roughness on the surface of the electrode after imprinting. Apart from SEM, there are also other characterization methods including AFM, contact angle measurements, ellipsometry etc., that can be used to characterize the surface after imprinting. By this way, it can be ensured that the imprinting process is successful and that template cavities are formed on the surface. Within these cavities, the template can bind with high specificity and affinity.

After injecting the standard solutions into the capacitive system, an average of the last five readings was calculated automatically by the software, and the calibration graphs were obtained by plotting the change in capacitance vs. the concentration of the analyte. The decrease in registered capacitance arose from the binding of the template. The more molecules that bind to the gold electrode surface, the higher the reduction in total capacitance, according to the general principle of capacitive measurements. Figure $\mathbf{5}$ and Figure $\mathbf{6}$ show that with increasing concentration of the analyte, the $\Delta \mathrm{C}$ increases as expected. The dynamic range (between which is the concentration range where the system is useful for the detection of a specific target) and the limit of detection (LOD) can be evaluated by analyzing these graphs. According to Figure 6 , the bacteriophage imprinted capacitive biosensor can detect bacteriophages in the concentration range of $10^{1}-10^{5} \mathrm{pfu} / \mathrm{mL}$, with an LOD value of $10 \mathrm{pfu} / \mathrm{mL}$ in this study. Both Figure $\mathbf{5}$ and Figure $\mathbf{6}$ also highlight the necessity of measuring the calibration curve in the same interval required for the template concentration is supposed, since the linearity of the regression may vary over the concentrations (Figure 5), or have different slopes (Figure 6). It should also be noted that due to the low concentrations used, the system is quite sensitive to fluctuations (turbidity in sample, air draft, etc.), and therefore, it is recommended to run at least triplicates to reduce the potential of including outliers. For the same reason, the standard deviation can be quite significant for highly diluted samples, as seen in Figure 6.

(A)

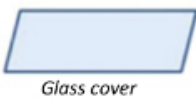

slip

(B)

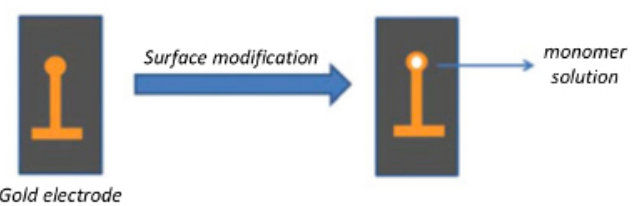

1. Surface modification

2. BSA immobilization

2. BSA immobilization

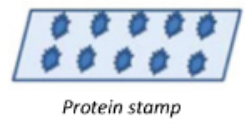

Protein stamp

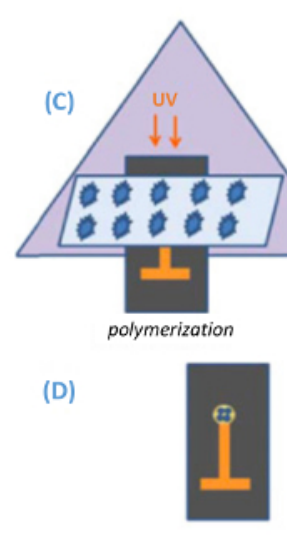

Removal of protein stamp
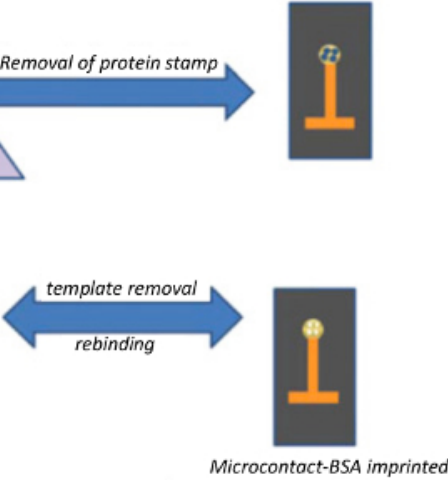

gold electrode

Figure 1. Schematic representation of the microcontact imprinting method. (A) Preparation of the glass cover slips (template stamps), (B) preparation of the capacitive gold electrodes, (C) microcontact imprinting of the template onto the gold electrode surface via UV-polymerization, and (D) removal of template from the electrode surface (Reproduced from Ertürk et al., Biotechnology Reports 2014 (3): 65 - 72 with permission). Please click here to view a larger version of this figure. 


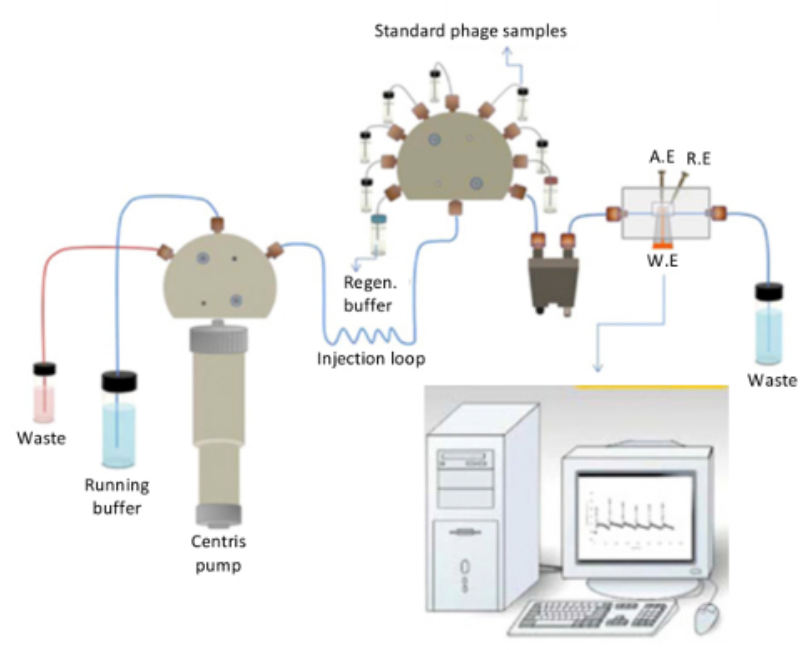

Figure 2. Schematic representation of the capacitive biosensor. The general layout of the capacitive biosensor used in this study (Reproduced from Ertürk et al., Biotechnology Reports 2014 (3): 65 - 72 with permission). Please click here to view a larger version of this figure.
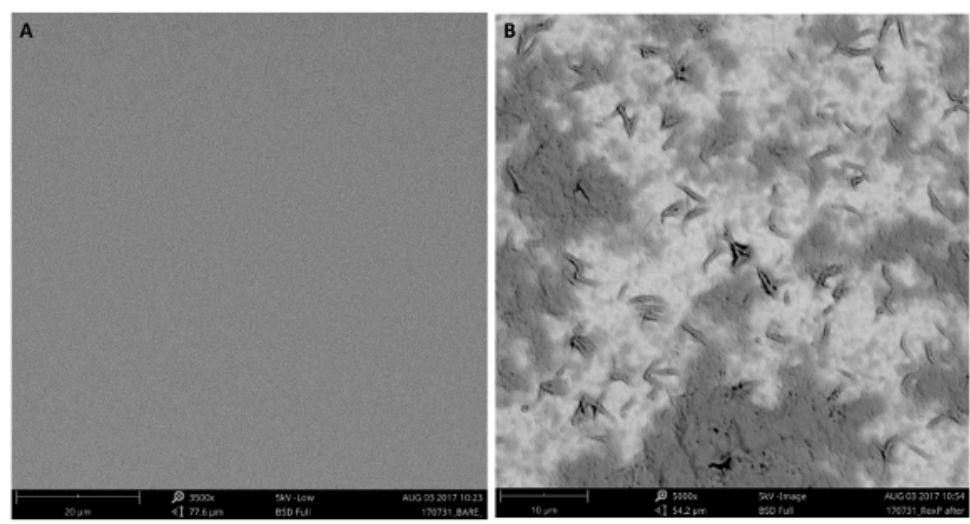

Figure 3. Scanning Electron Microscopy of protein imprinted electrodes. SEM images of $(\mathbf{A})$ a bare gold electrode $($ scale bar $=20 \mu m)$, and (B) a protein imprinted capacitive gold electrode (scale bar $=10 \mu \mathrm{m}$ ). Please click here to view a larger version of this figure. 

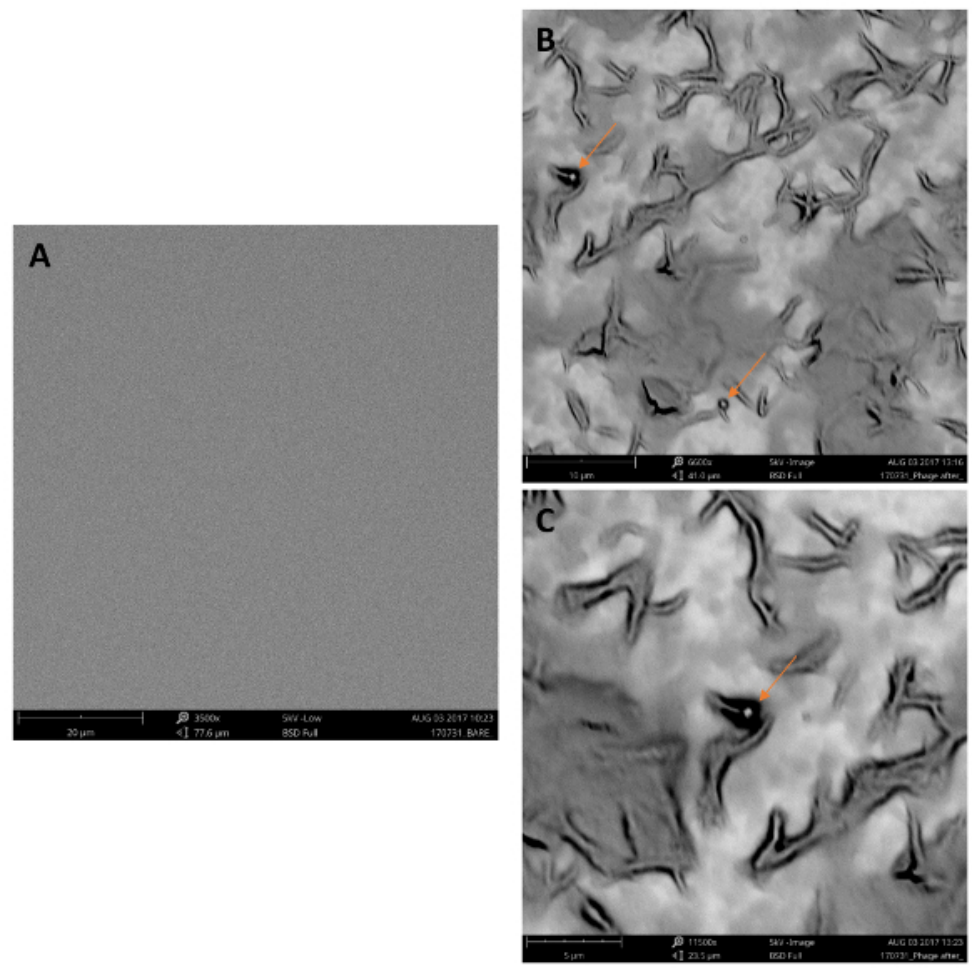

Figure 4. Scanning Electron Microscopy of bacteriophage imprinted electrodes. SEM images of a bare gold electrode $(\mathrm{scale}$ bar $=20 \mu \mathrm{m})$ (A), and a bacteriophage imprinted capacitive gold electrode in different magnifications $(6600 \mathrm{x}$, scale bar $=10 \mu \mathrm{m})(\mathbf{B})$, and $11,500 \mathrm{X}, \mathrm{scale}$ bar $=$ $5 \mu \mathrm{m})(\mathbf{C})$; arrows denote adhered bacteriophages). Please click here to view a larger version of this figure.

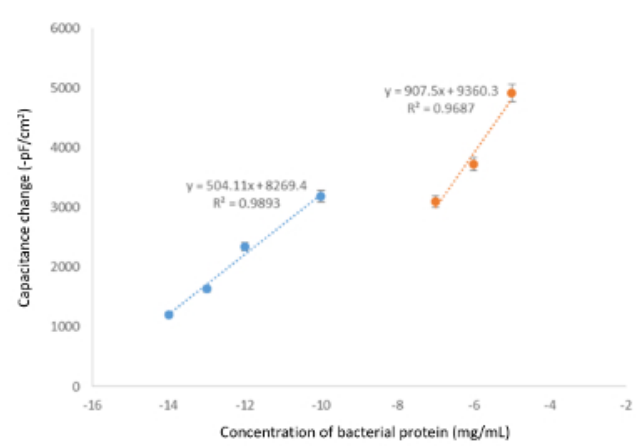

Figure 5. Effect of buffer composition for calibration graphs. Calibration graph showing the change in capacitance vs. a protein concentration in optimum conditions (Running Buffer: $50 \mathrm{mM}$ Tris- $\mathrm{HCl}, \mathrm{pH} 7.4$; Regeneration Buffer: $25 \mathrm{mM} \mathrm{glycine-HCl,} \mathrm{pH} 2.5$ including $50 \mathrm{mM}$ Tween-20; Flow rate: $100 \mu \mathrm{L} / \mathrm{min}$, Sample volume: $250 \mu \mathrm{L}$; T: $25^{\circ} \mathrm{C}$ ). Please click here to view a larger version of this figure. 


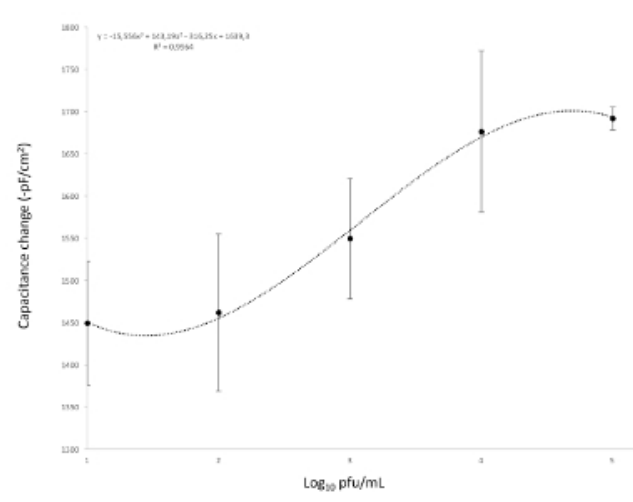

Figure 6. Representative calibration curve for large biomacromolecules. Calibration graph that shows the change in capacitance vs. bacteriophage concentration in optimum conditions (Running Buffer: $10 \mathrm{mM}$ phosphate, $\mathrm{pH} 7.4$; Regeneration Buffer: $25 \mathrm{mM}$ glycine-HCl, pH 2.5 including $50 \mathrm{mM}$ Tween-20; Flow rate: $100 \mu \mathrm{L} / \mathrm{min}$, Sample volume: $250 \mu \mathrm{L}$; T: $25^{\circ} \mathrm{C}$ ) Please click here to view a larger version of this figure.

\section{Discussion}

When this method is carried out, there are some critical steps that must be considered while following the protocol. One critical step is the cleaning step with acidic piranha solution. Step 2.1 must not be more than $10 \mathrm{~min}$. The template solution for step $1.4 \mathrm{must}$ not exceed $0.1 \mathrm{mg} /$ $\mathrm{mL}$, since these values have been optimized previously. Cyclic voltametric scans must not exceed 15 cycles in order to obtain the optimum thickness. For step 3.1.3, 1.5 $\mu \mathrm{L}$ is an optimized value. This value must not be higher for this specific type of electrode. If the UV curing system has a power of $400 \mathrm{~W}$, then the polymerization must be performed for a maximum of $10-15 \mathrm{~min}$. As soon as the APS (initiator) is added to the solution after TEMED, the subsequent step must be performed very quickly to avoid immediate polymerization (step 3.2.5).

One of the most critical steps is the removal of the template stamp from the surface after UV polymerization. If this step is not performed properly, there is a risk that the polymeric film on the surface of the electrode may be removed with the stamp. Therefore, it is recommended to immerse the electrode and the protein stamp on top in a solution of water after the polymerization, then remove the stamp very slowly and carefully from the surface (step 3.1.6).

Based on the template used, modifications in the type and ratio of monomers used (functional monomer and cross-linker) may be assessed in terms of generating higher sensitivity. This must be determined empirically. Further, the affinity binding of the template molecule usually involves several different interactions simultaneously. Therefore, this may lead to problems during the regeneration steps. If the bound template is not released from the surface properly, this may influence the reusability of the electrode for further analysis. These multipoint affinities may also result from binding via weaker interactions. In such systems, non-specific binding may take place, which can negatively influence the selectivity of the system ${ }^{16}$. These are common, and general, limitations of the method.

Apart from these specific limitations, there are many significant advantages of the discussed method over existing methods. While RIAs, ELISAs, and fluorometric measurements are very sensitive, they require the usage of labeled material (either template or detector), while the biosensor is completely label-free. These methods are also more expensive and time-consuming. A biosensor approach allows for rapid, parallel synthesis of MIPs in different compositions at the same time ${ }^{16}$. Since only a few microliters of monomer solution is required for preparation, the method is convenient when using expensive or otherwise limited monomers. Further, single MIP electrodes can be used for approximately 80 analyses without a significant decrease in the performance, which is significantly higher than other existing methods ${ }^{30}$. Existing methods also suffer, in varying degrees, of low sensitivity and selectivity, while the described method allows for detection and quantification of molecules in the pM range with high selectivity.

Due to the cost-effectiveness, the ease of operating the instrument, and the real-time sensitive detection in a short time compared to existing methods, the biosensors are very promising point-of care detection systems under field conditions; e.g., for environmental monitoring and for applications in developing countries. In many applications within diagnosis of disease, real-time, sensitive, selective, and rapid detection of a biomarker in a complex mixture such as serum is required ${ }^{15,25}$. Here, biosensors are superior to existing methods, in particular, due to their robustness and sensitivity. Specifically for the detection of infectious agents, bacteriophages are recently regarded as alternative biorecognition element for biosensors due to their host bacteria specificity ${ }^{33,34,35}$. Replacement of antibodies with bacteriophages is very promising in order to reduce the cost and increase the stability even further ${ }^{36}$. Such a system will also allow for the detection and quantification of specific phages in the environment and from clinical samples. Due to the prevalence of bacteriophages, and their ability to transduce bacteria with antibiotic resistance genes ${ }^{37,38}$, such a method may be valuable studying the spread of resistant bacterial.

\section{Disclosures}

The authors have nothing to disclose.

\section{Acknowledgements}

Maria Baumgarten (IQ Biotechnology Platform, Infection Medicine, Lund University) is acknowledged for performing and providing scanning electron micrographs. This work was supported by grants from The Swedish Research Council Formas (2017-00100) as part of the European 
Third Joint Programming Initiative on Antimicrobial Resistance (JPIAMR) call "Transmission Dynamics." The funders had no role in the study design, interpretation, writing, preparation of the manuscript, decision to submit, or decision to publish the work.

\section{References}

1. Lin, T. Y., Hu, C. H., \& Chou, T. C. Determination of albumin concentration by MIP-QCM sensor. Biosensors and Bioelectronics. 20 (1), 75-81, (2004).

2. Berggren, C., Bjarnason, B., \& Johansson, G. Capacitive Biosensors. Electroanalysis. 13 (3), 173-180, (2001).

3. Zhang, S., Garcia-D'Angeli, A., Brennan, J. P., \& Huo, Q. Predicting detection limits of enzyme-linked immunosorbent assay (ELISA) and bioanalytical techniques in general. The Analyst. 139 (2), 439-445 (2014).

4. Mattiasson, B., Teeparuksapun, K., \& Hedström, M. Immunochemical binding assays for detection and quantification of trace impurities in biotechnological production. Trends in Biotechnology. 28 (1), 20-27 (2010).

5. Limbut, W., Hedström, M., Thavarungkul, P., Kanatharana, P., \& Mattiasson, B. Capacitive biosensor for detection of endotoxin. Analytical and Bioanalytical Chemistry. 389 (2), 517-525 (2007).

6. Ertürk, G., Berillo, D., Hedström, M., \& Mattiasson, B. Microcontact-BSA imprinted capacitive biosensor for real-time, sensitive and selective detection of BSA. Biotechnology Reports. 3, 65-72 (2014).

7. Arshady, R., \& Mosbach, K. Synthesis of substrate-selective polymers by host-guest polymerization. Macromolecular Chemistry and Physics. $182(2), 687-692,(1981)$.

8. Andersson, L. I. Molecular imprinting: developments and applications in the analytical chemistry field. Journal of chromatography. B, Biomedical sciences and applications. 745 (1), 3-13 (2000).

9. Li, X., \& Husson, S. M. Two-dimensional molecular imprinting approach to produce optical biosensor recognition elements. Langmuir: the ACS Journal of Surfaces and Colloids. 22 (23), 9658-9663 (2006).

10. Alexander, C., Davidson, L., \& Hayes, W. Imprinted polymers: artificial molecular recognition materials with applications in synthesis and catalysis. Tetrahedron. 59 (12), 2025-2057 (2003).

11. Kryscio, D. R., \& Peppas, N. A. Surface imprinted thin polymer film systems with selective recognition for bovine serum albumin. Analytica Chimica Acta. 718, 109-115 (2012).

12. Inerowicz, H. D., Howell, S., Regnier, F. E.,Reifenberger, R. Multiprotein immunoassay arrays fabricated by microcontact printing. Langmuir. 18 (13), 5263-5268, (2002).

13. Lin, H. Y., Hsu, C. Y., Thomas, J. L., Wang, S. E., Chen, H. C., \& Chou, T. C. The microcontact imprinting of proteins: The effect of crosslinking monomers for lysozyme, ribonuclease A and myoglobin. Biosensors and Bioelectronics. 22 (4), 534-543, (2006).

14. Liao, P. C., Tyan, Y. C., Wang, C. Y., Hsu, J. F., Chou, T. C., \& Lin, H. Y. Assessing the binding selectivity of molecularly imprinted polymer artificial antibodies by mass spectrometry-based profiling system. Journal of Biomedical Materials Research Part A. 91 (2), 597-604, (2009).

15. Ertürk, G., Hedström, M., Tümer, M. A., Denizli, A., \& Mattiasson, B. Real-time prostate-specific antigen detection with prostate-specific antigen imprinted capacitive biosensors. Analytica Chimica Acta. 891, 120-129 (2015).

16. Ertürk, G., \& Mattiasson, B. From imprinting to microcontact imprinting-A new tool to increase selectivity in analytical devices. Journal of Chromatography. B, Analytical Technologies in the Biomedical and Life Sciences. 1021, 30-44 (2016).

17. Ertürk, G., \& Mattiasson, B. Molecular Imprinting: The Creation of Biorecognition Imprints on Biosensor Surfaces. Advanced Molecularly Imprinting Materials. 523-560 (2017).

18. Janczuk-Richter, M., et al. Long-period fiber grating sensor for detection of viruses. Sensors and Actuators B: Chemical. 250, 32-38 (2017).

19. Kropinski, A. M., Mazzocco, A., Waddell, T. E., Lingohr, E., \& Johnson, R. P. Enumeration of bacteriophages by double agar overlay plaque assay. Methods in Molecular Biology. 501, 69-76 (2009).

20. Meillan, M., et al. Self-assembled monolayer for AFM measurements of Tobacco Mosaic Virus (TMV) at the atomic level. RSC Adv. 4 (23), 11927 (2014).

21. Ymeti, A., et al. Fast, ultrasensitive virus detection using a Young interferometer sensor. Nano Letters. 7 (2), $394-397$ (2007).

22. Wei, Y., Wong, L. P., \& Toh, C.-S. Fuel cell virus sensor using virus capture within antibody-coated nanochannels. Analytical Chemistry. 85 (3), 1350-1357 (2013).

23. Guliy, O. I., et al. Immunodetection of bacteriophages by a piezoelectric resonator with lateral electric field. Applied biochemistry and microbiology. 52 (4), 457-463 (2016).

24. Reta, N., Michelmore, A., Saint, C., Prieto-Simón, B., \& Voelcker, N. H. Porous silicon membrane-modified electrodes for label-free voltammetric detection of MS2 bacteriophage. Biosensors \& Bioelectronics. 80, 47-53 (2016).

25. Ertürk, G., Özen, H., Tümer, M. A., Mattiasson, B., \& Denizli, A. Microcontact imprinting based surface plasmon resonance (SPR) biosensor for real-time and ultrasensitive detection of prostate specific antigen (PSA) from clinical samples. Sensors and Actuators B: Chemical. 224, 823-832 (2016).

26. Lebogang, L., Mattiasson, B., \& Hedström, M. Capacitive sensing of microcystin variants of Microcystis aeruginosa using a gold immunoelectrode modified with antibodies, gold nanoparticles and polytyramine. Microchimica Acta. 181 (9-10), 1009-1017 (2014).

27. Loyprasert, S., Hedström, M., Thavarungkul, P., Kanatharana, P., \& Mattiasson, B. Sub-attomolar detection of cholera toxin using a label-free capacitive immunosensor. Biosensors \& Bioelectronics. 25 (8), 1977-1983 (2010).

28. Teeparuksapun, K., Hedström, M., Wong, E. Y., Tang, S., Hewlett, I. K., \& Mattiasson, B. Ultrasensitive detection of HIV-1 p24 antigen using nanofunctionalized surfaces in a capacitive immunosensor. Analytical Chemistry. 82 (20), 8406-8411 (2010).

29. Labib, M., Hedström, M., Amin, M., \& Mattiasson, B. A capacitive biosensor for detection of staphylococcal enterotoxin B. Analytical and Bioanalytical Chemistry. 393 (5), 1539-1544 (2009).

30. Ertürk, G., Hedström, M., \& Mattiasson, B. A sensitive and real-time assay of trypsin by using molecular imprinting-based capacitive biosensor. Biosensors \& Bioelectronics. 86, 557-565 (2016).

31. Ertürk, G., Uzun, L., Tümer, M. A., Say, R., \& Denizli, A. Fab fragments imprinted SPR biosensor for real-time human immunoglobulin G detection. Biosensors \& Bioelectronics. 28 (1), 97-104 (2011).

32. El-Sharif, H. F., Phan, Q. T., \& Reddy, S. M. Enhanced selectivity of hydrogel-based molecularly imprinted polymers (HydroMIPs) following buffer conditioning. Analytica Chimica Acta. 809, 155-161 (2014). 
33. Wang, F., et al. Detection of Salmonella Typhimurium on Spinach Using Phage-Based Magnetoelastic Biosensors. Sensors (Basel, Switzerland). 17 (2) (2017).

34. Chin, B. A., et al. Rapid detection of small quantities of specific bacteria using phage-based wireless biosensors. 201610 th International Conference on Sensing Technology (ICST). , 1-5 (2016).

35. Park, M.-K., \& Chin, B. A. Novel Approach of a Phage-Based Magnetoelastic Biosensor for the Detection of Salmonella. enterica serovar Typhimurium in Soil. Journal of Microbiology and Biotechnology. 26 (12), 2051-2059 (2016).

36. Mack, J. D., Yehualaeshet, T., Park, M.-K., Tameru, B., Samuel, T., \& Chin, B. A. Phage-Based Biosensor and Optimization of Surface Blocking Agents to Detect Salmonellatyphimurium. on Romaine Lettuce. Journal of food safety. 37 (2), e12299 (2017).

37. Colomer-Lluch, M., Jofre, J., \& Muniesa, M. Antibiotic resistance genes in the bacteriophage DNA fraction of environmental samples. Plos One. 6 (3), e17549 (2011).

38. Lood, R., Ertürk, G., \& Mattiasson, B. Revisiting antibiotic resistance spreading in wastewater treatment plants - bacteriophages as a much neglected potential transmission vehicle. Frontiers in microbiology. 8 (2017). 